\title{
Perusal of Load Balanced Routing Protocols in MANETs with Simulation of Working of MANETs
}

\author{
Meenakshi Moza \\ Faculty of Engineering \& \\ Technology \\ Manav Rachna International \\ University \\ Faridabad, India
}

\author{
Bakul Choudhary \\ Faculty of Engineering \& \\ Technology \\ Manav Rachna International \\ University \\ Faridabad, India
}

\begin{abstract}
MANETs work without any backbone connection to any static network. They have dynamic network topology with limited physical security and energy constrained operation. The nodes of the network behave in a proper way if the load on each node is equally distributed or distributed according to its processing capabilities. Thus, load balancing becomes an irremovable constraint in MANETs. Hence to save the network from congestion, delay and loss of packets load balancing is very important. Many protocols based on various properties have been raised for load balancing. In this paper a comparative study of these protocols is done. An NS 2 simulation of basic working of MANETs is also done.
\end{abstract}

\section{General Terms}

Manets, Load, Nodes

\section{Keywords}

Load balancing, Routing protocols

\section{INTRODUCTION}

Wired solution have been around for a long time but now there in an increasing demand for wireless solutions that too the ones that could be set up without any backbone connections. This requirement calls for ad hoc solutions or temporary networks that could be set up on the go. The examples could be mining expeditions, gaming consoles etc. Ad hoc networks are not connected to any static network and it can be a kind of any small network or LAN. A MANET (Mobile Ad Hoc Networks) is thus a collection of mobile devices that communicate over wireless links. The basic properties of MANETS are as given below:
a) Dynamic network topology
b) Autonomous \& Infrastructure less
c) Multihop routing
d) Energy Constrained Operations
e) Limited Physical Security
f) Self Creating, Self Organizing and Self Administrating
g) Operating as stand-alone network or with one or multiple point of attachment to cellular network or the internet.

A vital part of ad hoc network is load balancing at each node. The networking becomes a complicated job if heavy load is given to a node with less processing capabilities. Few nodes with high processing capability may be sitting idle or has completed their task. Thus, Load Balancing is the process of improving the network performance by re-distribution of load among the nodes.

\section{NEED OF LOAD BALANCING}

Load balancing evenly distributes the load in the network according to the processing capabilities of the node. Multi path routing balances load better in ad hoc networks than single path routing does, which is done by first selective shortest path obtained. But multipath routing can be done only in the presence of huge number of nodes between source destination pair of nodes. It is economical in discovering and maintaining a large number of paths. Use of multipath for load balancing instead of single path may increase reliability through redundancy.

The basic issues settled while improving the load balancing at each node can be summarized as given below:
a) Optimal resource utilization
b) Maximize throughput
c) Minimize response time
d) Increase lifetime
e) Avoid Overload due to

Load Balancing also decreases degrading of performance
a) Congestion
b) Delay
c) Power loss

\section{TYPE OF LOAD IN NETWORKING}

While networking if we classify the load that is prevalent on the components of the network, it could be defined as:

3.1 Load on the Channel where multiple nodes contend to access the same channel.

3.2 Load on the Node refers to the computation or processing in which the node is busy. It can also be summed as nodal activity.

3.3 Load on the Neighboring Node is the activity of the neighboring nodes. 


\section{MEASUREMENT OF LOAD}

Load Balanced Routing Protocols measure load on the basis of following points:

\subsection{Number of Active Paths}

The number of active paths supported by the node defines the business of the node. The higher the active routing paths, the more the node involved in forwarding the packets from various sources.

\subsection{Accessing the Channel}

It refers to the degree to successful contention of the wireless media.

\subsection{Size of the Traffic}

The amount of packets available at the node to be forwarded and its neighbors.

\subsection{Delay in Processing Packets}

The processing time taken to forward the packets to the next node is the delay in sending of message. It called packet queuing.

\section{TYPES OF LOAD BALANCED ROUTING PROTOCOL}

Load Balanced Routing Protocols can be divided into three types:

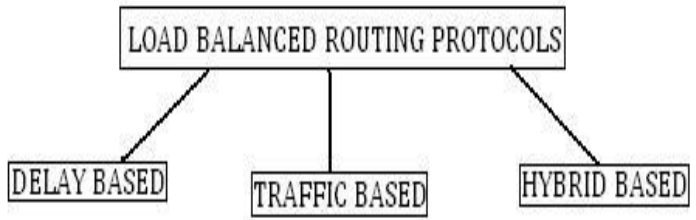

Fig 1: Load Balanced Routing Protocols

\subsection{Delay Based}

In this protocol load balancing is done by trying to avoid nodes with high delay.

\subsection{Traffic Based}

Load balancing in these protocols is achieved by evenly distributing the packets among various neighboring nodes.

\subsection{Hybrid Based}

Here, the features of two above mentioned protocol types is used in hybrid based protocols.

\section{REVIEW OF AD HOC ROUTING PROTOCOLS}

Ad Hoc Routing Protocols can be divided into four types:

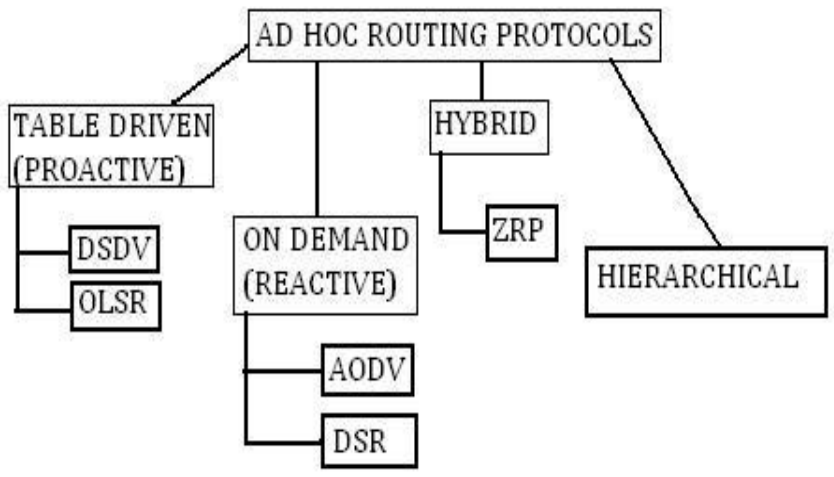

Fig 2: Ad-Hoc Routing Protocols

\subsection{Table Driven (Proactive)}

This protocol maintains fresh lists of destinations and their routes by periodically distributing routing tables throughout the network. It can be characterized into two types:

\subsubsection{Destination Sequenced Distance Vector $(D S D V)$}

Each entry in the routing table has a sequence number, which is even if the link is present. The sequence number is generated by destination. Routing information is distributed among nodes by sending full dumps infrequently and small increments frequently.

\subsubsection{Optimized link State Routing Protocol $(O L S R)$}

IP routing protocol optimized for ad hoc networks. It's a link state routing protocol that uses hello and topology control messages to discover and disseminate link state information throughout the mobile ad hoc network. Individual nodes use this information to compute next destination hop.

\subsection{On Demand (Reactive)}

This protocol finds the route on request by flooding the network with rout request packets. It can be characterized into two types:

\subsubsection{Ad-Hoc on Demand Distance Vector Routing $(A O D V)$}

It's a routing protocol for ad hoc networks. The node that needs connection broadcasts request for route. Other nodes forward this message and record the node which needs the route. When any node hears such a message and it already has route to the requested destination it sends the message backward through temporary route to the requesting node. When the link fails, the routing error is passed on to transmitting node and the process repeats.

\subsubsection{Dynamic Source Routing (DSR)}

It's a routing protocol for wire mesh networks. It forms a route on demand when a transmitting node requests one. It uses source routing instead of relying on routing tables. All the routing information is maintained at mobile nodes. It has two major phases - Route Discovery and Route Maintenance.

\subsection{Hybrid}

This protocol combines the advantages of both proactive and reactive protocols. It's specified as ZRP protocol. 


\subsubsection{Zone Routing Protocol (ZRP)}

It was designed to speed up delivery and reduce processing overhead. If the packets destination is the same zone as that of the originating zone, then the proactive routing table is used to deliver the packet immediately. If the route extends outside the packet's originating zone then the reactive protocol takes over. It reduces the overhead for those routes.

\subsection{Hierarchical}

In this type of protocol the choice of proactive or reactive routing depends upon the hierarchic level in which node resides.

\section{STUDY OF VARIOUS LOAD}

\section{BALANCED ROUTING PROTOCOLS}

The various Load Balanced Routing Protocols and their specifications are as follows:

\subsection{Associativity Based Routing [5]}

$>$ DSDV, Traffic based, Multipath

$>$ Route selected on the basis of associativity states of nodes.

$>$ Free from deadlock and packet duplicates

$>$ Beaconing requirement can result in additional power consumption

$>$ Working-

- $\quad$ Source sends broadcast query (BQ) in search of nodes that have route to destination.

- Intermediate nodes receiving BQ append their address and associativity ticks with their neighbors with route relaying load (RRL) information to $\mathrm{BQ}$. The BQ arriving at destination contains all the information.

- Acceptable routes are the ones where node RRL does not exceed above max allowable value.

- Destination chooses the most stable route \& sends reply back to source node via this route.

\subsection{Alternate Path Routing [6]}

$>$ ZRP, Traffic based, Multipath

$>$ Applied to telephone networks, ATM, and the internet to support survivability \& load balancing

$>$ Less benefit in single channel

$>$ Balancing the load by routing the traffic over the set of disjoint route.

\subsection{Load Sensitive Routing [7]}

$>$ DSR, Traffic based, Single path

$>$ Network load information as the main path selection criteria

$>$ Does not require periodic exchange of load information among neighboring nodes
$>$ Uses redirection method to find better paths effectively

$>$ When used path becomes congested, this protocol tries to find a light weight path

> Source node continues to send data along congested path until better path is formed.

$>$ No consideration for burst traffic.

\subsection{Load Balanced Ad Hoc Routing [8]}

$>$ DSR, Traffic based, Single path

$>$ For delay sensitive application

Finds out route with least traffic \& load

$>$ Four stages of algorithm

- $\quad$ Route Discovery

- $\quad$ Path Maintenance

- Local Connectivity management

- Cost function Computation

$>$ Best path calculated based on min traffic load in transmitter and minimum interference by neighboring nodes

> Mainly used for connection less application.

\subsection{Energy Consumption Load \\ Balancing [9]}

$>$ DSR, Delay Based, Multipath

$>$ Power consumption rate at each node must be evenly distributed to maximize the lifetime of ad hoc mobile networking

$>$ Some nodes become involved in routing packets for many source destination pair

$>$ Energy resource of such nodes is depleted faster than other nodes

$>$ This protocol makes balanced energy consumption available by calculating energy consumption rate at each node and choosing alternative route where a node is overburdened

$>$ Used only in the environment of lower power level

\subsection{Traffic Size Aware Routing [10]}

$>$ Virtual Path Routing, Traffic Based, Multipath

$>$ Traffic size measured in bytes

$>$ Node maintains entry for every active virtual path

$>$ Load metrics is calculated which is the sum of all the traffic

$>$ This protocol distributes the traffic among the network nodes to avoid the creation of highly congested areas. 


\subsection{Simple Load Balancing Approach}

[11]

AODV + DSR, Traffic based, Single Path

$>$ Mobile packets may deliberately give up forwarding packets to save their own energy

$>$ Solution to avoid selflessness of nodes is payment schema called Protocol independent Fairness Algo (PIFA)

$>$ In this nodes earn credit for forwarding packets

$>$ Server node called Credit Manager (CM) manages Credit Database (CDM)

$>$ Nodes periodically report to the $\mathrm{CM}$ on the number of packets forwarded

$>$ Packets can be originated by the nodes only when they have enough packets which is earned by forwarding other packets
PIFA detects malicious nodes which cheats on the number of packets forwarded to acquire more credits

\subsection{Correlated Load Aware Routing} [12]

$>$ AODV, Traffic based, Multipath

$>$ Considers traffic load through and around neighboring nodes

$>$ Traffic load is based on traffic passing through this node \& neighboring node

$>$ When RREQ reaches destination node it selects node with min traffic as the best route

$>$ In presence of more than one route, shortest hop route is selected

$>$ Suited with networks with low mobility

Table 1. Comparison of Load Balanced Routing Protocols

\begin{tabular}{|c|c|c|c|c|c|c|}
\hline $\begin{array}{l}\text { S. } \\
\text { No }\end{array}$ & $\begin{array}{l}\text { Load Balanced Protocol } \\
\text { Under Study }\end{array}$ & $\begin{array}{l}\text { Parent } \\
\text { Routing } \\
\text { Protocol }\end{array}$ & $\begin{array}{l}\text { Type Of } \\
\text { Load } \\
\text { Balanced } \\
\text { Protocol }\end{array}$ & $\begin{array}{l}\text { Type Of } \\
\text { Path }\end{array}$ & Good Points/Uses & Drawbacks \\
\hline 1 & Associativity based Routing & DSDV & $\begin{array}{l}\text { Traffic } \\
\text { based }\end{array}$ & Multipath & $\begin{array}{c}\text { Free from packet } \\
\text { duplicates \& deadlocks }\end{array}$ & $\begin{array}{l}\text { Beaconing requirement } \\
\text { can result in additional } \\
\text { power consumption }\end{array}$ \\
\hline 2 & Alternate Path Routing & ZRP & $\begin{array}{l}\text { Traffic } \\
\text { based }\end{array}$ & Multipath & $\begin{array}{l}\text { Applied to ATM, } \\
\text { telephone networks }\end{array}$ & $\begin{array}{c}\text { Less beneficial in single } \\
\text { channel }\end{array}$ \\
\hline 3 & Load Sensitive Routing & DSR & $\begin{array}{l}\text { Traffic } \\
\text { based }\end{array}$ & Single path & $\begin{array}{c}\text { Does not require } \\
\text { periodic exchange of } \\
\text { load information from } \\
\text { neighboring nodes }\end{array}$ & $\begin{array}{l}\text { No consideration for } \\
\text { burst traffic }\end{array}$ \\
\hline 4 & $\begin{array}{l}\text { Load Balanced Ad-Hoc } \\
\text { Routing }\end{array}$ & DSR & $\begin{array}{l}\text { Traffic } \\
\text { based }\end{array}$ & Single path & $\begin{array}{l}\text { For delay sensitive } \\
\text { applications }\end{array}$ & $\begin{array}{l}\text { Used for connection } \\
\text { less application }\end{array}$ \\
\hline 5 & $\begin{array}{c}\text { Energy Consumption Load } \\
\text { Balancing }\end{array}$ & DSR & Delay Based & Multipath & $\begin{array}{l}\text { Makes power available } \\
\text { evenly at each node }\end{array}$ & $\begin{array}{l}\text { Used in the } \\
\text { environment of lower } \\
\text { power levels }\end{array}$ \\
\hline 6 & Traffic Size Aware Routing & $\begin{array}{l}\text { Virtual } \\
\text { Path }\end{array}$ & $\begin{array}{l}\text { Traffic } \\
\text { based }\end{array}$ & Multipath & $\begin{array}{c}\text { Distributes traffic } \\
\text { among network nodes } \\
\text { to avoid creation of } \\
\text { highly congested areas. }\end{array}$ & $\begin{array}{l}\text { Node maintains entry } \\
\text { for every active virtual } \\
\text { path }\end{array}$ \\
\hline 7 & $\begin{array}{c}\text { Simple Load Balancing } \\
\text { Approach }\end{array}$ & $\begin{array}{l}\text { AODV+ } \\
\text { DSR }\end{array}$ & $\begin{array}{l}\text { Traffic } \\
\text { based }\end{array}$ & Single path & $\begin{array}{c}\text { Solution to avoid } \\
\text { selfishness of nodes. }\end{array}$ & $\begin{array}{c}\text { Extra energy } \\
\text { consumption in creation } \\
\text { of Credit Manager }\end{array}$ \\
\hline 8 & $\begin{array}{c}\text { Correlated Load Aware } \\
\text { Routing }\end{array}$ & AODV & $\begin{array}{l}\text { Traffic } \\
\text { based }\end{array}$ & Multipath & $\begin{array}{l}\text { Considers traffic load as } \\
\text { on concerned node and } \\
\text { around neighboring } \\
\text { node }\end{array}$ & $\begin{array}{l}\text { Suited for networks } \\
\text { with low mobility }\end{array}$ \\
\hline
\end{tabular}




\section{SIMULATION BASED STUDY OF WORKING OF MANETS}

A simulator is a kind of software that imitates the selected part of the behavior of the real world and normally used as a tool for research and development. Here, open source NS 2 simulator is used to imitate the basic working of the MANETs. Simulation is done using AODV routing protocol. Four nodes were used to study flow of packets in MANETs.

\subsection{Specifications for simulation parameter}

Simulation Time:

10.0

Channel Type:

Wireless Channel

Propagation Model:

Two Ray Ground

Phy Type(Network I/F Type):

WirelessPhy

MAC Protocol Type:

802_11

Interface Queue type:

Queue/DropTail/PriQueue

Link Layer Type:

LL

Antenna Type:

OmniAntenna

Number Of Mobile Nodes:

4

Max Packet in Queue:

50

Routing Protocol:

AODV

Agent Trace:

$\mathrm{ON}$

Router Trace:

ON

MAC Trace:

$\mathrm{ON}$

Movement Trace:

$\mathrm{ON}$

Bandwidth_

$11 \mathrm{Mb}$

Datarate

$11 \mathrm{Mb}$

\subsection{The graphical scenario for four nodes} is as given

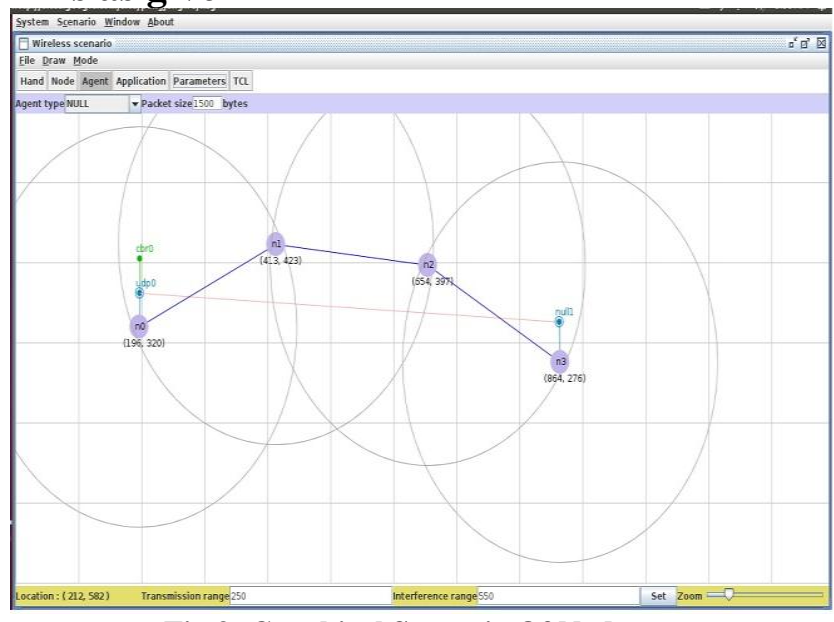

Fig 3: Graphical Scenario Of Nodes

\subsection{The flow of data packets is shown with help of NAM animator}

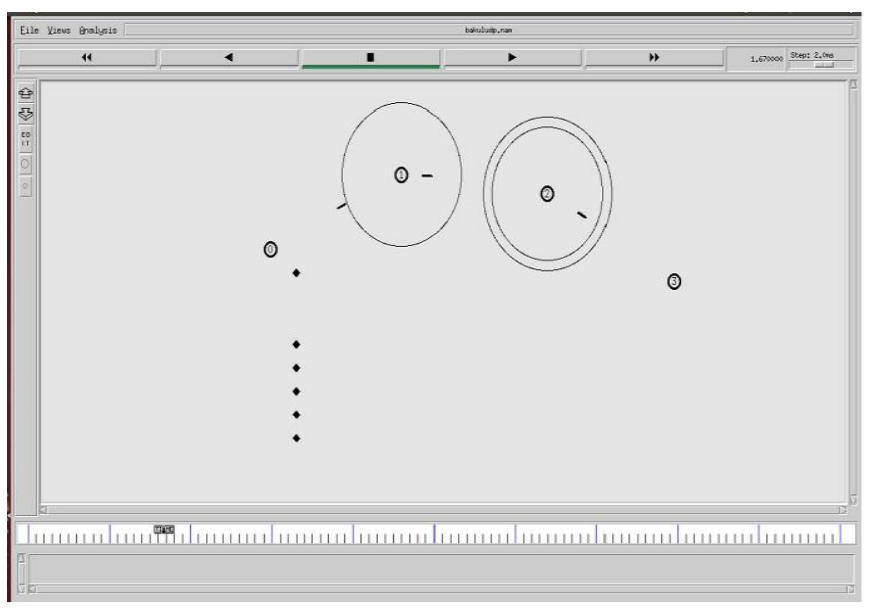

Fig 4: Flow of Data Packets

\subsection{The graphs plotted for the simulation are given below}

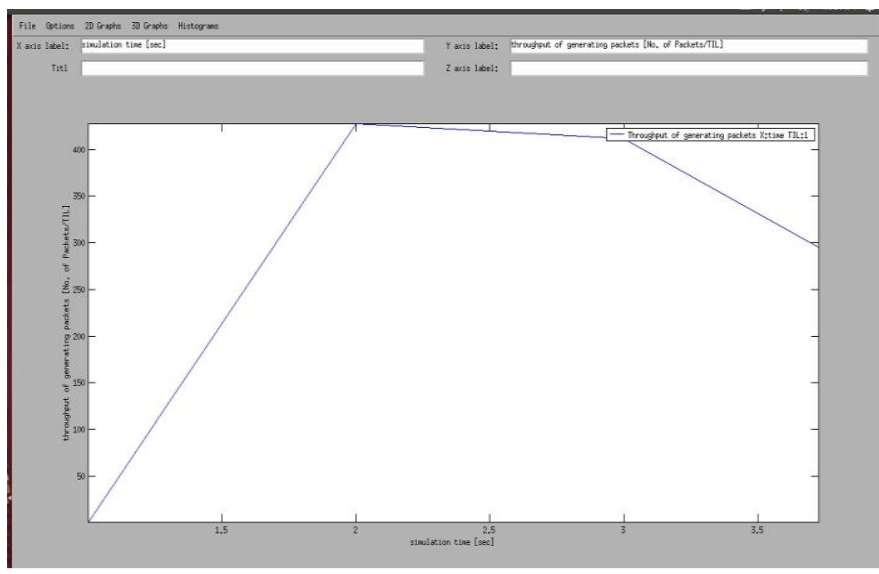

Fig 5: Simulation Time Vs Throughput Of Generating Packets

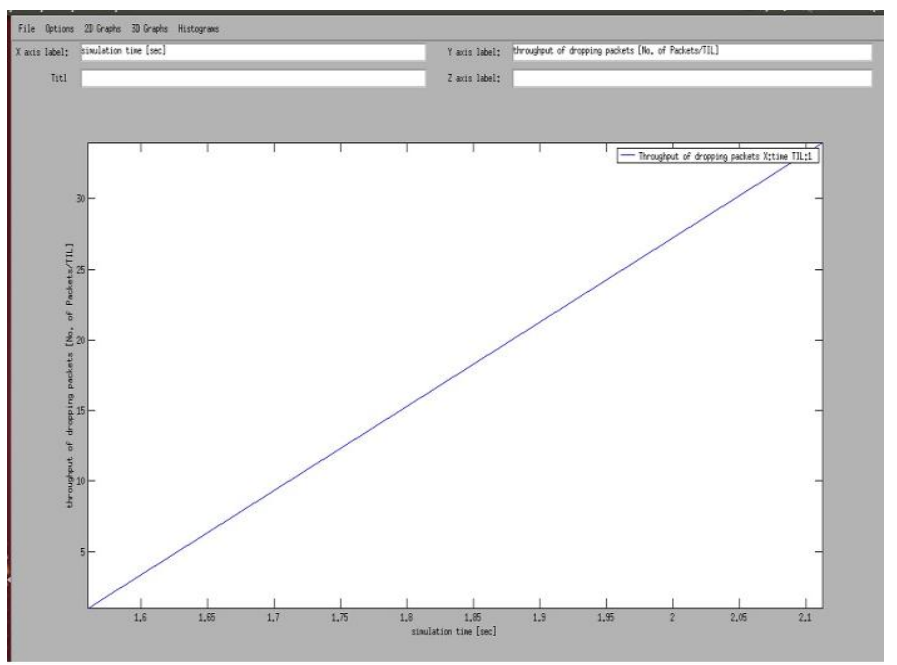

Fig 6: Simulation Time Vs Throughput of Dropping Packets 


\section{CONCLUSION}

Some important Load Balanced routing protocols has been discussed here. There types and basic working were studied. It is thus known that the act of load balancing is important for congestion free, delay free working of MANETs. Load balancing helps in improving the performance of the network.

Many research areas in this field which deserve further investigation include

- robustness,

- security

- energy efficiency,

- low overhead,

- reliability and

- scalability.

Effective and efficient solutions to these issues require the design and development of new multipath routing protocols in MANETs.

\section{REFERENCES}

[1] P.Elayarasu MCA and V. Saravanan, "Efficient Resource Allocation with Improved QoS And Load Balancing In MANET",IJERT, ISSN: 2278-0181, Vol. 2 Issue 7, July - 2013I. S. Jacobs and C. P. Bean, "Fine particles, thin films and exchange anisotropy," in Magnetism, vol. III, G. T. Rado and H. Suhl, Eds. New York: Academic, 1963, pp. 271-350.

[2] Pradeep, B.S. and S.Soumya, "A new method for load balancing and QOS in on demand protocols in the MANETs perspective" International Journal of Advanced Networking and Applications, Volume: 01, Issue: 04,Pages: 275-281,2010.

[3] M. Ali, B. G Stewart, A. Shahrabi, A. Vallavaraj, "Enhanced QoS Support In Mobile Ad hoc Networks Using Multipath Routing Backbones", in proceedings of 6th IEEE GCC Conference \& exhibition, Dubai, UAE, Feb 2011, pp: $315-318$.
[4] Soundararajan et. al. "Adaptive Multi-Path Routing for Load Balancing in Mobile Ad Hoc Networks" Journal of Computer Science, vol. 8 (5), , ISSN 1549-3636, pp. 648- 655, 2012.

[5] CHAI-KEONG TOH "Associativity-Based Routing for Ad-Hoc Mobile Networks" Wireless Personal ommunications 4: 103-139, 1997. 1997 Kluwer Academic Publishers. Printed in the Netherlands.

[6] M. R. Pearlman, Z. J. Hass, P. Sholander, S. S. Tabrizi, “ On the impact of alternate path routing for load balancing in mobile ad-hoc networks", Proc. Of 2000 First Annual Workshop on Mobile and Ad Hoc Networking and Computing, Mobihoc 2000, Boston, MA, USA, August 2000, pp. 3-10.

[7] K. Wu, J. Harms, "Load Sensitive Routing for Mobile Ad Hoc Networks", Proc. IEEE ICCCN'01, Phoenix, AZ Oct. 2001, pp. 540-546.

[8] H. Hassanein, and A. Zhou, "Load-aware destinationcontrolled routing for MANETs", Elsevier Computer Communications 26(2003), pp. 1551-1559.

[9] H. K. Cho, E. S. Kim, and D-W Kang, "A Loadbalancing Routing Considering Power Conservation in Wireless Ad-Hoc Networks", Proc. Of the $16^{\text {th }}$ International Workshop on Database and Expert Systems Applications, DEXA'05.

[10] Abdulrahman H.Altalhi, Golden G. Richard,III, "LoadBalanced Routing through Virtual Paths: Highly Adaptive and Efficient Routing Scheme for Ad Hoc Wireless Networks".

[11] Y. Yoo and S. Ahn, "A Simple Load-Balancing Approach in Secure Ad Hoc Networks", ICOIN 2004, LNCS 3090, pp. 44-53, 2004.

[12] Kyungshik Lim, Hyun-Kook Kahng, "A Correlated Load Aware Routing Protocol in Mobile Ad Hoc Networks", ECUMN 2004, LNCS 3262, pp. 227-236, 2004. 